\title{
Erratum to: Income and individual deprivation as predictors of health over time
}

\author{
Fiona Imlach Gunasekara • Kristie N. Carter • \\ Peter Crampton · Tony Blakely
}

Published online: 17 September 2013

(C) Swiss School of Public Health 2013

\section{Erratum to: Int J Public Health (2013) 58:501-511 DOI 10.1007/s00038-013-0450-9}

We (the authors) apologise that unfortunately some of the references have been interchanged incorrectly in the text and are missing in the reference list. These errors were made by the authors in the review phase of this paper and are not the fault of the journal.

Missing references and the pages they should be referenced on:

- Berthoud R, Bryan M, Bardasi E (2004) The dynamics of deprivation: the relationship between income and material deprivation over time. Institute for Social and Economic Research at the University of Essex for the Department for Work and Pensions, Leeds

Reference: page 502 and page 509 instead of Yang et al. 2012.

- Bisgaier J, Rhodes K (2011) Cumulative adverse financial circumstances: Associations with patient health status and behaviors. Health Soc Work 36(2):129-137

The online version of the original article can be found under doi:10.1007/s00038-013-0450-9.

F. Imlach Gunasekara · K. N. Carter $(\bowtie) \cdot$ T. Blakely Health Inequalities Research Programme, School of Medicine and Health Sciences, University of Otago, Wellington,

New Zealand

e-mail: kristie.carter@otago.ac.nz

P. Crampton

Division of Health Sciences, University of Otago, Dunedin,

New Zealand
Reference: page 502 instead of Gottschalk and Huynh 2010.

- Bradshaw J, Mayhew E (2011) The measurement of extreme poverty in the European Union. European Commission, Brussels

Reference: page 503 instead of Nedjat et al. 2012.

- Gibb SJ, Fergusson DM, Horwood LJ (2012) Childhood family income and life outcomes in adulthood: findings from a 30-year longitudinal study in New Zealand. Soc Sci Med 74(12):1979-1986. doi:10.1016/ j.socscimed.2012.02.028

Reference: page 502 instead of Bechtel et al. 2012.

- Gottschalk P, Huynh M (2010) Are earnings inequality and mobility overstated? The impact of nonclassical measurement error. Rev Econ Stat 92(2):302-315

Reference: page 509 instead of Gibb et al. 2012.

- Jenkins SP (2011) Changing fortunes: income mobility and poverty dynamics in Britain. Oxford University Press, Oxford

Reference: page 509 instead of Yoo et al. 2009.

- Magadi M, Middleton S (2007) Severe child poverty in the UK. Save the Children Fund, London

Reference: page 503 instead of de Castro et al. 2010.

- Pfoertner T-K, Andres H-J, Janssen C (2011) Income or living standard and health in Germany: different ways of measurement of relative poverty with regard to self-rated health. Int $\mathbf{J}$ Public Health 56:373-384 
Reference: page 502 instead of Lukiyanova and Oshchepkov 2012.

- Pischke J-S (1995) Measurement error and earnings dynamics: some estimates from the PSID validation study. J Bus Econ Stat 13(3):305-314

Reference: page 509 instead of Sedgwick 2012.

- Salmond C, Crampton P (2012) Measuring socioeconomic position in New Zealand. J Prim Health Care 4(4):271-280

Reference: page 502 and page 509 instead of Schulz et al. 2006.
- Singh-Manoux A, Ferrie JE, Chandola T, Marmot M (2004) Socioeconomic trajectories across the life course and health outcomes in midlife: evidence for the accumulation hypothesis? Int $\mathrm{J}$ Epidemiol 33(5):1072-1079

Reference: page 502 instead of Tubeuf et al. 2012.

- Whelan CT, Layte R, Maitre, B. (2004) Understanding the mismatch between income poverty and deprivation: A dynamic comparative analysis. Eur Sociol Rev 20(4):287-302

Reference: page 502 instead of Dowd 2012. 